NURSES ATTITUDES

\title{
Passing the audition - the appraisal of client credibility and assessment by nurses at triage
}

\author{
Bernie Edwards and David Sines
}

\begin{abstract}
Aim. This paper presents the findings of one aspect of a larger study aiming to build a substantive grounded theory of the process of initial assessment at triage.

Background. Prioritisation at triage within emergency departments centres primarily on assessing the threat to physiological function of people presenting with health-care problems. This approach presumes that clinical reasoning strategies reside exclusively within the health-care practitioner, with the patient playing no active part in the process.

Design. A grounded theory/symbolic interactionist methodology.

Methods. Thirty-eight recordings were made of live triage encounters involving 14 emergency nurses from two demographically distinct emergency departments. At the end of the relevant shift, those encounters in which the nurses were involved were replayed to them. The recording was stopped after each question or comment by the nurse who was then asked to say what they were thinking at the time. The nurses' thoughts were recorded, transcribed and analysed using the constant comparative method, in which hypotheses are generated and continually modified in the light of incoming data until a conceptual story line, or theory, is produced.

Results. The findings suggest that the outward clinical signs of problems presenting to the emergency department were not viewed by nurses as neutral manifestations of the pathology itself but as a conscious or unconscious portrayal of patients' physical discomfort and their perception of the nature of the problem. The way in which patients and carers depict their problems is used by triage nurses to determine the credibility of the clinical information they provide.

Conclusion. Triage can be regarded as a process in which nurses act as an adjudicating panel, judging the clinical data before them through the appraisal of the way patients act out their problems and narrate their stories.

Relevance to clinical practice. Nursing practice and research need to account for the patient's contribution to the decisionmaking process at triage.
\end{abstract}

Key words: assessment, decision-making, grounded theory, triage

Accepted for publication: 21 December 2006

\section{Introduction}

Triage is a unique form of nurse-patient encounter demanding a rapid, superficial, yet accurate assessment and disposition. This is undertaken by nurses geographically separated from the rest of the care process in conditions of uncertainty and with minimal information (Gerdtz \& Bucknall 1999).

Authors: Berine Edwards, PhD, RN, RNT, Practice Development Fellow, IHCS, Bournemouth University, Royal London House, Christchurch Road, Bournemouth, UK; David Sines, PhD, RN, RMN, RNT, PGETH, FRCN, FRSA, Professor of Community Health Nursing and Executive Dean Faculty of Health and Social Care, London South Bank University, London, UK
Prioritisation at triage in emergency departments centres primarily on the threat to physiological function of people presenting with health-care problems. Frequently using published guidelines, nurses are required to seek and discriminate between a limited number of signs and symptoms to allocate a level of clinical priority (Mackway-Jones (chair) 1997). Furthermore, much research has gone into appraising the 
reliability of nurses to accurately allocate presenting problems to such categories (Goransson et al. 2006).

However, within this almost universally accepted paradigm, there is an underlying assumption that clinical reasoning strategies reside exclusively within the health-care practitioner with the patient playing no active role in the process other than as a passive purveyor of data. This paper will report findings from a study into the process of nurse reasoning at triage within emergency departments that calls this assumption into question. The paper will posit that triage can, alternatively, be regarded as a performance whereby triage nurses act as an adjudicating panel judging the clinical data before them through the appraisal of the way patients act out their problems and narrate their stories.

\section{Method}

The aim of this study was to build a substantive grounded theory of how emergency nurses undertake the process of initial assessment when making triage dispositions. Over a period of nine months, 38 recordings were made of live triage encounters involving 14 emergency nurses from two demographically distinct emergency departments. At the end of the relevant shift, those encounters in which the nurses were involved, were replayed to them. The recording was stopped after each question or comment by the nurse who was then asked to say what they were thinking at the time. The nurses' thoughts were recorded, transcribed and subsequently used as the basis for analysis.

\section{Sampling and ethical approval}

Following ethics committee approval, permission was gained from senior staff in each department to seek a volunteer sample from among those nurses who regularly undertook triage. Written consent was gained from the volunteers who ranged in experience of emergency care from three to 20 years. As the study involved the presence of a video camera, each was informed that if at any time they had concerns about the content of the triage encounter, they were free to turn off the recording and it would not be used in the study. In addition, letters outlining the purpose and process of the study were sent to all staff members. During the periods of recording, posters informing the public of the research were displayed at the respective reception areas. Written permission to make and use the recording for research purposes was sought from patients both before and after triage (General Medical Council 1997). To minimise disruption to patient care and flow patients who were confused, acutely ill or distressed were excluded from the study.

\section{Data analysis}

Data analysis was organised around the paradigm model proposed by Strauss and Corbin $(1990,1998)$. At the heart of this process lies the central tenet that theory is generated from and grounded in the data. The data are analysed using the constant comparative method during which data collection and analysis occur simultaneously. As hypotheses are generated, so they are tested against and modified in the light of incoming data for fit using open, axial and selective coding. The aim is to generate a story line or basic process that explains the central phenomenon and encapsulates all that is going on. This paper will report on the discovery of the main intervening condition (Strauss \& Corbin 1998) within triage, that of 'Appraising Client Credibility'.

\section{Findings}

\section{Initial visualizing and client credibility}

The findings of this study confirmed that the process of triage assessment began prior to the triage encounter, commencing as soon as the nurse sighted the person. This initial visualisation was based almost exclusively on an intuitive appraisal of the 'look of the patient', an immediate subjective impression centring on visible manifestations of threatening pathology or indicative of high levels of distress. The aim was to differentiate between those who were in immediate danger from those who 'looked alright' and were safe to be subject to the 'normal' triage process:

You do sort of make a mental, quick assessment of the patient as they come through the door, before you actually ask them a question. (Participant 1)

The 'look of the patient' was constructed around the presence of physiological or behavioural signs indicating the extent to which the person was incapacitated or distressed by the problem. In particular, nurses observed the patient's posture, general demeanor, freedom of movement and facial expression to gauge the extent to which they were 'happy' or distressed' to gauge the impact of the problem:

I was just looking at him generally seeing whether he was smiling, happy, miserable, that sort of thing. (Participant 4)

However, nurses in this study were influenced in their assessment by the credence they gave to the source of that data, namely the clients themselves (Table 1):

Immediately he looks all right, he doesn't look as if he's in pain. One's gut feeling is that it's not too bad an injury anyway. If they're coming in and they're limping and they're obviously in distress your 
Table 1 Characteristics influencing triage nurses' appraisal of the credibility of patients and carers presenting to the emergency department

Degree of congruence between the level of distress portrayed by the patient and/or carer and the perceived extent of the problem

General appearance - posture, gait, mobility, state of dress, body type, hygiene

Self-care undertaken prior to attending emergency

Time between the onset of the problem and attending

Whether the person attends with problems that the emergency department can directly deal with

Evidence of previous treatment

Nature of any care administered by referring agencies, such as GP

Triage nurses' beliefs about the purpose of their service

immediate reaction is to think there's something wrong with the boy. But he was fine he didn't look distressed as if he was worried about it. (Participant 5)

This quote suggests that, when appraising the impact of the problem, the extent to which the patient looked distressed was related to the degree of worry he felt about his injury. The fact that the patient was 'not looking distressed' suggests that the nurse believed the patient had the option to portray his problem differently. In other words, if the patient really was worried, he would choose to present himself in a distressed way. This form of reasoning was particularly evident when appraising children, whereby nurses supplemented their 'initial visualisation' of the child 'walking-into' the triage room by comparing this with their observation of the child 'walking-out' into the waiting area:

It was interesting to note as the child was leaving he decided to hop out whereas he had walked in, he was limping but he'd walked in ... but he obviously had discomfort. (Participant 3 )

In this example, the nurse made a clear distinction between the six-year-old's hopping and his limping. The former was attributed to a decision the child had made, a deliberate choice to maximise the problem to those around him. This is contrasted with the limp which, because the child was unaware of having an audience, is assumed to have resulted directly from physical discomfort. Thus, only the limp was regarded as credible data.

These findings imply that in responding to the presence of distress, the nurses adjudged that the outward signs of presenting problems were not simply neutral manifestations of the underlying pathology. Instead, the nurses regarded these signs as a conscious or unconscious portrayal by the patient of their physical discomfort and their perception of, or concern about, the nature of the problem and how others would perceive it.

\section{Patient appearance and client credibility}

Triage involves nurses making rapid decisions regarding the health status of an unknown person in the minimum of time. Denied the opportunity of getting to know the patient, nurses drew on observation of a person's general appearance and the quality of inter-personal relationships in an attempt to ground the problem within the patient's life-world:

She was elderly, it took her a few minutes to gather herself, pick her stuff up off the chair. Not very old and frail but she was elderly and she wasn't with anybody and she had a bandage round her wrist. (Participant 6)

Thus, although the nurse noticed that the movements of this person were slow and lacking in freedom, they are not viewed as visible signs of distress resulting from a precipitant event, but rather are accounted for as 'normal' and not of immediate concern by virtue of the fact that the person has been defined as 'old'. Despite the fact that the nurse did not regard this person as 'very old' or 'frail', the use of these words suggests that the nurse possesses prior expectations as to how someone of this age would appear.

In the next extract, the nurse draws on inferences as to the 'credibility' of those attending, both as people and as carers from the state of dress and hygiene, both acting as measures of the extent to which people took an interest in themselves and those for whom they acted as carers:

The mum looked quite smart, little one looked a typical normal little boy, um, not overly scruffily dressed. Dad looked a bit on the scruffy side but whether he'd come home from work or something you don't know. A family unit appeared (laughs). (Participant 13)

By not being 'too smart' or 'too scruffy', the child in the quote fulfilled the criteria as to what that nurse believed constituted 'normal' and 'typical' for a male child of that age. In looking 'quite smart', mum is contrasted with 'dad'. However, rather than regarding the father's appearance as a deviation from 'normal', the nurse justified to herself his appearance by making assumptions about the role of the father within the group both to the notion of his having been at work and to the physical nature of that work. As a result, the nurse concluded that this comprised a 'family unit', one that did not raise concerns as to their interest in and their ability to care for, the child. Because there was no deviation from what the nurse regarded as 'normal', there is no doubt expressed as to their 'credibility' or to the ease of the subsequent interaction.

According to Tanner et al. (1993), nurses come to learn through experience how patients typically respond to a given problem. They then compare these 'usual presentations' with 
the person in front of them to identify potential variations from the usual course that will need to be accounted for in the triage process. Such inferences draw heavily upon personally constructed typologies, assumptions both about what is 'normal' for different social groupings and also how those constructions of perceived normality may or may not have an impact upon the health of the group members. However, these were not static judgements, but were refined and negotiated through the process of narrating and appraising the story.

\section{Client credibility and narrating the story}

\section{Self-care and credibility}

When narrating their stories, the credibility of the patients was determined through the appraisal of their self-care prior to seeking help and their reasons for attending the emergency department. In both instances, the extent to which the patient or carer's behaviour aligned with what the nurse deemed to be appropriate was the major criteria for judging the worth of any given story:

Mum sounds as if she's being terribly sensible. It happened yesterday, she gave it 24 hours to see if it would improve. She put ice on it she was doing all the right things. She goes on to say that she gave him regular paracetomol so she's a switched on cookie. (Participant 2)

The nurse awarded the mother the title of 'sounding sensible', because she had been doing all the 'right things'. She did not come up to the department immediately, but undertook selfcare in the form of recommended first aid and analgesia. She allowed time to see if the injury 'got better', and therefore, was one that constituted 'emergency work' and yet not too long so as to be outside the 48-hour limit.

Delay in presenting to emergency following injury was also used as criteria for adjudication, especially injuries more than 48-hours old:

The fact is that it wasn't too bad then and it is now ... The fact that it was yesterday is always a clue that, that did something a day or two ago they've had time to think about it. Again sometimes it can be that the time is never appropriate when the injury's happened to come to emergency, then when there's a convenient slot sometimes they'll troll on up. (Participant 5)

In this instance, while the nurse accepted that the symptoms had got worse, she also believed that delay could sometimes arise from clients wanting to attend at a convenient time. This implies that the nurse construed a casual attitude to problems on the part of those who delay; the reasoning being that if the problem was that concerning the person would attend straightaway and not wait. The implication is that, by having time to 'think about it', the patient has had the opportunity to select not only when he is going to attend but how he is going to present the problem. The derisory tone of the phrase 'troll on up' suggests a level of casualness that belies any level of concern. For these reasons, the nurse regarded the person who had attended after a delay as less credible and someone who was exploiting the constant availability of the emergency department.

\section{Credibility and the reasons for attending emergency}

Triage nurses not only expected patients to attend within a reasonable time frame, but they were also supposed to know what services were available within the emergency department and to attend only those problems that emergency departments could directly deal with:

A lady with another eye infection that we will refer to the eye clinic. Not really appropriate to come to emergency that's why I felt it was important to impress on her that the GP's the first line of call. (Participant 2)

Visual evidence of previous treatment also caused the nurse to doubt whether the presentation constituted credible emergency work:

This was a patient that should have been referred straight to fracture clinic ... He'd got a full bay cast on he was non-weight bearing, using crutches. The fact that he had a 'bay-cast' on indicated that it was an old injury or at least he had been seen and he'd been sorted and he'd been seen by an orthopaedic person. (Participant 9)

Clearly, the presence of a limb cast and crutches identified the injury as one that has not just taken place. Thus, from the nurse's point of view, the problem has been sorted in the sense that a specialist long-term management plan has been initiated and there is nothing the emergency department could or should do.

Even the sight of documentation influenced nurses' immediate responses. Apart from the content of any formal documentation, the very fact of their presence influenced the way nurses viewed the scenario. A General Practitioner letter and/or X-ray request card notified the nurse that the person had been recently assessed with a problem for which they had sought advice. The presence of an X-ray folder would locate the problem as one that was non-acute or old, and therefore, non-concerning. It also implied that the patient had been previously assessed and treated and cast doubt as to whether the person and/or the referring agency had followed the 'usual referral pathway':

The brown X-ray folder, it obviously wasn't one of our folders; it was obviously from another hospital. (Participant 12) 


\section{Credibility of referring agencies}

When people were referred to A \& E by other agencies, the same criteria of credibility that was placed by triage nurses on patients were placed equally upon those who sent them. In doing so, the nurses drew heavily upon their experiential knowledge of the usual pathway of care that each presenting problem should undergo and by whom, when and where it should be provided:

... She should have been referred to the orthopaedic team because such a straightforward orthopaedic referral ... I was getting cross at this point, not so much with patient, the patient's been told she's going to have an X-ray in emergency. The GP, if she has wanted to manage the patient like that she [GP] could have sent her up for an $\mathrm{X}$-ray years ago if it had been a chronic problem like that. But she [GP] chose to send the lady up to emergency for our opinion then it's up to us whether we X-ray her ankle or not. So I'm getting cross with the GP, it's just the lady saying 'she wants an X-ray'. (Participant 11)

In the latter example, the fact that the GP had informed the patient that she was attending A \& E for an X-ray when the nurse believed that decision should rest with the department provided extra grounds for discontent. It placed an obligation on the department to see the patient and undertake an X-ray, an obligation the nurse clearly felt they should not have to fulfil.

Furthermore, triage nurses saw themselves as 'evaluators' of the effectiveness of pre-emergency health care, frequently displaying a sceptical view of the quality of service GP and other community practitioners provided (see also Dale \& Green 1991, Gibney et al. 1995, Marsden 1998):

... I wanted to know if she was brewing a septicaemia or not from the infection she had in her face because she had taken antibiotics and yet her face had swollen up since. She'd obviously got an infection that hadn't been treated properly ... (Participant 14)

However, as previously stated, the appraisal of credibility was not static but rather continually negotiated during the triage encounter as this instance of a lady attending with a dental problem goes on to illustrate:

Just trying to get a history from her because dental problems aren't our forte. We don't have a dentist, if people come straight up with a dental problem I would feel like they were taking advantage of the system. But she'd obviously had an extraction and has got a dental appointment but is in severe pain and swelling... I know the problem people get with dentists in won't take on non-private patients and it's getting difficult to get an appointment. I do have sympathy for them although we don't always look after them we do quite often let them come through and at least give them pain killers and antibiotics, even if they don't get treatment. (Participant 14)

It was clear that, under normal circumstances, the nurse would regard anyone attending emergency with a dental problem as inappropriate and 'taking advantage of the system'. However, in this instance, through the relaying of her story, the patient was clearly able to argue the merit of her case in a way that persuaded the nurse to see the problem as legitimate. The nurse came to regard the fault as lying with the dental service and not with the person, who had made every effort to do as much of the 'right thing' as she was able to. In addition, the intensity and visibility of the symptoms plus the fact that they had got worse were also seen as mitigating factors.

\section{Discussion}

Triage nurses in this study were acutely aware that their assessment of any presenting problem was totally dependent upon how the problem was portrayed and narrated by the patient. The outward clinical signs depicted by patients were not viewed by nurses as neutral manifestations of the pathology itself, but as a conscious or unconscious portrayal of that pathology evolved from a combination of patients' physical discomfort and their perception of the nature of the problem. In short, triage nurses regarded the 'look' as an outward presentation that patients constructed in response to their own level of distress that served to persuade the nurse, to varying degrees, of the legitimacy of the patients' problem and their level of concern.

According to Goffman (1959), when an individual enters the presence of others, they commonly seek to acquire information about him. They will be 'interested in his socioeconomic status, his conception of self, his attitude toward them, his competence and his trustworthiness' (p. 1). When initiating social encounters, it will be in the interest of the individual to control the conduct of the others, especially their respective treatment of him, by influencing the definition of the situation that the others come to formulate. The individual does this by conveying to others the kind of impression that will lead them to act in accordance with his own plan; a process Goffman (1959) likens to a 'performance'.

Atkinson (1995) argues that, in the face of a performance, it is natural for any audience to feel sceptical of the impression the performer seeks to give, as people have to establish their credentials and the credence to be attached to their words (p. 117). Hughes (1988) suggests that this scepticism pervades all emergency nurses' dealings with their 
patients, attributing this to the frequency emergency nurses have to deal with those who may be less than honest in their presentations (Handysides 1996). For example, the nurses in Sbaih (1997b) study perceived their assessment of patients before they entered the emergency department as being more accurate because they felt that the patients had not begun to exaggerate their symptoms to the nurse.

Hughes (1988) suggests that, in many cases, evaluation of the patient's story depends on a fine-grained knowledge of social types and the typical motives and circumstances associated with problems of different kinds. Conclusions are drawn largely on the basis of readily available cues, for example, race, mode of dress, language, accents, word usage, cleanliness and smell (Roth 1972).

Grief and Elliott (1994) and Crouch and Dale (1994) discovered that emergency nurses display a hierarchy of preferences for specific types of patients. Sympathy and motivation to help declined and irritation increased with patients who were triaged as having primary-care problems, when there was a delay in presenting to the department and when difficulties associated with communication and patient demeanour were present. Grief and Elliott (1994) postulate that this tendency to group patients into categories of worthiness results from the frustration experienced in trying to provide a quality service in the face of ever-increasing attendances, the repetition of apparently low priority and non-urgent cases engendering negative feelings towards these patients.

Triage nurses in this study deemed people responsible not so much for the problem itself, but rather how they responded to the problem, in particular, where, when and how they accessed health-care services (Butler 1999). This is despite the plethora of research that attendance at emergency is influenced by a wide range of factors (Calnan 1983, Padgett \& Brodsky 1992, Green \& Dale 1992, Walsh 1995 , Rieffe et al. 1999, Welsh 2001a,b)

Benner et al. (1996) argue that this need for nurses to determine the validity of the patient's complaint confirms nursing's subjugation to the influence of medicocentrism. This latter perspective views patient stories as subjective and a potentially inaccurate source of data, thereby encouraging health-care practitioners to assess patient complaints primarily in terms of the underlying pathology, at the expense of the person's psychological or social well being (Benner \& Wrubel 1989).

Sbaih $(1997 a, b)$ posits that nurses new to the emergency setting learn how to make sense of the organisation of emergency work through listening to and observing experienced nurses. In this way, nurses build up a repertoire of 'maxims', rules or stocks of knowledge, about the unique taken-for-granted aspects of the emergency world. In particular, they internalise notions as to how patients are expected to present with certain illnesses and injuries associated with what is known as emergency work. What is clear from this current study is that, not only do nurses need to know the maxims of emergency work, but nurses presume that the patients are also aware of them.

This stance is compounded through the triage nurses' position as gatekeeper to the emergency-care service. Thus, when presenting themselves to the emergency department, patients know that the triage nurse has the power to decide whether and when they will be seen. Clients need to present their problems in a manner that will convince the nurse of the legitimacy of their problem. However, the public do not know how the nurse can be convinced as they do not know the nurses' objectives and strategies and hence what the meaning of any interaction has for the nurse. Professional dominance is thus perpetuated through the triage nursepatient encounter owing to the parties' unequal access to each others' perspectives (Hak 1994).

However, Johnson and Webb (1995a,b) challenge what they see as the dominant view within the nursing literature that it is personal traits, such as social class or diagnosis, which act as predictors for evaluating social worth. Observing the interactions between ward staff and patients, they discovered that the classification of patients was open to change and renegotiation on the basis of their responses to the programme of care and nurses' perceptions of the level of nursing work individuals generated. The authors concluded that patients are active in the social construction of their identity and frequently employ complex skills in presenting their 'selves' as they want to be seen.

The evidence from this current study suggests that triage nurses' judgements are not based solely on a static phenomenon of pre-existing patient criteria, but come to be revised as the performance is played out throughout the interaction. The patient 'performance' is thus regarded by triage nurses as a distorted representation of an underlying objective clinical reality and is judged according to its credibility to sustain the clinical impression or other features that may give rise to nursing concern. It is mediated by the perceived degree of congruence between the features of the performance and the anticipated clinical findings.

The judgements nurses make are influenced by their personal values, selected perceptions, their view of 'man' and their beliefs as to the nature of their work, in this case, triage (Brooks \& Thomas 1997, Morgan \& Whelan 2000). According to Sbaih (2001), there is a clash of cultures within emergency nursing between the patient-centered ideology of government policy, their professional aspiration and 
emergency nurses' sense of mission rooted in what they understand to be the nature of their work. Guttman et al. (2001) discovered that, even among emergency staff, the notion of what constitutes emergency work is contested with the internal debate revolving around three contesting ideologies. The ideology of service, with its professional obligation to promote the welfare of all people in need of medical attention, the ideology of specialism, that those trained and working in emergency care should devote their attention to emergency cases and the ideology of efficiency, where medically non-urgent problems are viewed as inefficient and an abuse of a costly health-care resource.

These personal philosophies explain how and why clinical situations are 'figured out' and consequently acted upon in particular ways. They especially influence the cues that are noticed and the priorities that are set. Each philosophical orientation can be perceived as orchestrating a different clinical reasoning path for the nurse (Kools et al. 1996).

\section{Limitations of the study}

The use of a self-selected sample carries with it the potential for bias in that those who come forward may be motivated by a hidden agenda or represent people with a particular worldview. In addition, it is significant to note that in keeping with the general demography of the areas served by the departments, the recorded encounters involved white, Caucasian patients. It would be interesting to explore the extent the reasoning of triage nurses varied with cultural considerations. Thus, the results can only be said to be truly representative of the informants and emergency departments involved.

\section{Conclusion}

The paper has argued that triage can be regarded as a performance whereby triage nurses act as an adjudicating panel judging the clinical data before them through the appraisal of the way patients act out their problems and narrate their stories. Specifically, triage nurses have been shown to be guided in their decision making by their inherent beliefs about the nature of emergency work and the rules that people attending the service are required to follow. This approach appears to align with a postpositivist epistemology (Guba \& Lincoln 1998), a belief that there exists an underlying objective clinical and social reality but one that is obscured by the overlays of the patient performance. The resulting pragmatic ideology acts as a filter to nurses' 'visualizing work' determining what constitutes legitimate data and hence what is deserving of nursing attention.
Such a perspective aligns with all the existing research on the decision-making process that focusses exclusively on the reasoning process of the professional at the expense of the patient, in a manner not dissimilar to the studies in communication (Jarrett \& Payne 1995). For, as Atkinson (1995) states, too many advocates of decision-making models also assume that professional actions are to be explained primarily in terms of mental acts and bonded events of deciding. This implies that patients are passive within the decision-making process, merely acting as an unreliable and sometimes reluctant, repository of information.

In contrast, what this study has highlighted is that patients are active in the construction of the presentation and interpretation of their problem. In this sense, triage can be seen as a socially constructed interactive process, the outcomes of which are determined by the way in which the participants create, elicit, interpret and negotiate the meaning of the presenting problem. A specific outcome of this study is that future research on decision making needs to focus equally on the patients' contribution to this process.

\section{Contributions}

Study design: BE; data collection and analysis: BE \& DS and manuscript preparation: BE, DS.

\section{References}

Atkinson P (1995) Medical Talk and Medical Work. Sage, London. Benner P \& Wrubel J (1989) The Primacy of Caring: Stress and Coping in Health and Illness. Addison-Wesley, Menlo Park, California.

Benner P, Tanner C \& Chesla C (1996) Expertise in Nursing Practice: Caring, Clinical Judgement and Ethics. Springer Publishing, New York.

Brooks E \& Thomas S (1997) The perception and judgement of senior baccalaureate student nurses in clinical decision-making. Advances in Nursing Science 19, 50-69.

Butler J (1999) The Ethics of Health Care Rationing. Cassell, London.

Calnan M (1983) Managing 'minor' disorders: pathways to a hospitals accident and emergency department. Sociology of Health and Illness 5, 149-167.

Crouch R \& Dale J (1994) Identifying feelings engendered during triage assessment in the accident and emergency department: the use of visual analogue scales. Journal of Clinical Nursing 3, 289-297.

Dale J \& Green J (1991) How do nurses working in hospital accident and emergency departments perceive general practitioners? A study in six English hospitals. Archives of Emergency Medicine 8, 210-216.

General Medical Council (1997) Making and Using Visual and Audio Recordings of Patients. General Medical Council, London. 
Gerdtz M \& Bucknall T (1999) Why we do the things we do: applying decision-making frameworks to triage practice. Accident and Emergency Nursing 7, 50-57.

Gibney D, Murphy A, Smith M, Bury G \& Plunkett P (1995) Attitudes of Dublin accident and emergency doctors and nurses towards the services offered by local general practitioners. Journal of Accident and Emergency Medicine 12, 262-265.

Goffman E (1959) The Presentation of Self in Everyday Life. Penguin, Harmondsworth.

Goransson K, Ehrenberg A, Marklund B \& Ehnfors M (2006) Emergency department triage: is there a link between nurses' personal characteristics and accuracy in triage decisions? Accident and Emergency Nursing 14, 83-88.

Green J \& Dale J (1992) Primary care in accident and emergency general practice: a comparison. Social Science and Medicine 35, 987-995.

Grief C \& Elliott R (1994) Emergency nurses' moral evaluation of patients. Journal of Emergency Nursing 20, 275-279.

Guba E \& Lincoln Y (1998) Competing paradigms in qualitative research. In The Landscape of Qualitative Research: Theories \& Issues (Denzin N \& Lincoln Y eds). Sage, Thousand Oaks, California, pp. 195-220.

Guttman N, Nelson M \& Zimmerman D (2001) When the visit to the emergency room is medically non-urgent: provider ideologies and patient advice. Qualitative Healthcare Research 11, 161178.

Hak T (1994) The interactional form of professional dominance. Sociology of Health and Illness 16, 469-488.

Handysides G (1996) Triage in Emergency Practice. Mosby-Year Book, St. Louis, Missouri.

Hughes D (1988) When doctor knows best: some aspects of nurse/ doctor interaction in a casualty department. Sociology of Health and Illness 10, 1-22.

Jarrett N \& Payne S (1995) A selective review of the literature on nurse-patient communication: has the patient's contribution been neglected? Journal of Advanced Nursing 22, 72-78.

Johnson M \& Webb C (1995a) Rediscovering unpopular patients: the concept of social judgement. Journal of Advanced Nursing 21, $466-475$.

Johnson M \& Webb C (1995b) The power of social judgement: struggle and negotiation in the nursing process. Nurse Education Today 15, 83-89.
Kools S, Mccarthy M, Durham R \& Robrecht L (1996) Dimensional analysis: broadening the conception of grounded theory. Qualitative Health Research 6, 312-330.

Mackway-Jones K (chair) (1997) Emergency Triage. BMJ Publishing, London.

Marsden J (1998) Decision making in emergency by expert nurses. Nursing Times 94, 62-65.

Morgan J \& Whelan L (2000) Triage: a retrospective evaluation. Emergency Nurse 8, 22-29.

Padgett D \& Brodsky B (1992) Psychosocial factors influencing nonurgent use of the emergency room: a review of the literature and recommendations for research and improved service delivery. Social Science and Medicine 35, 1189-1197.

Rieffe C, Oosterveld P, Wijkel D \& Wiefferink C (1999) Reasons why patients bypass their GP to visit a hospital emergency department. Accident and Emergency Nursing 7, 217-225.

Roth J (1972) Some contingencies of the moral evaluation and control of clientele: the case of the hospital emergency service. American Journal of Sociology 77, 839-856.

Sbaih L (1997a) The work of accident \& emergency nurses: Part1 - an introduction to the rules. Accident \& Emergency Nursing 5, 28-33.

Sbaih L (1997b) The work of accident and emergency nurses: Part 2 emergency maxims: making emergency work unique and special. Accident \& Emergency Nursing 5, 81-87.

Sbaih L (2001) Shaping the future: reforming routine emergency nursing work. Accident and Emergency Nursing 9, 266-273.

Strauss A \& Corbin J (1990) Basics of Qualitative Research. Sage, Newbury Park, California.

Strauss A \& Corbin J (1998) Basics of Qualitative Research, 2nd edn. Sage, Thousand Oaks, California.

Tanner C, Benner P, Chelsa C \& Gordon D (1993) The phenomenology of knowing the patient. IMAGE: The Journal of Nursing Scholarship 25, 273-280.

Walsh M (1995) The health belief model and use of accident and emergency services by the general public. Journal of Advanced Nursing 22, 694-699.

Welsh J (2001a) Great expectations: a survey of the expectations of self-referred patients and their accompanying relatives and friends of an emergency service: Part one. Emergency Nurse 9, 33-39.

Welsh J (2001b) Great expectations: a survey of the expectations of self-referred patients and their accompanying relatives and friends of an emergency service: Part two. Emergency Nurse 9, 34-39. 